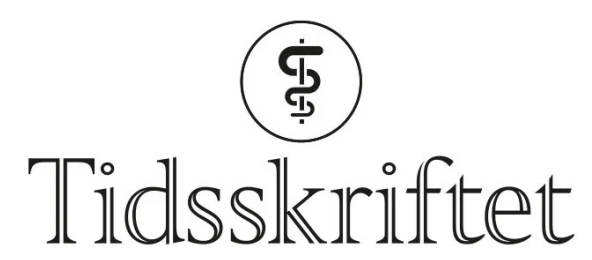

DEN NORSKE LEGEFORENING

\title{
Kultur og helse: «How America got physical»
}

ANMELDELSER

ERIK EKKER SOLBERG

Overlege, Diakonhjemmet sykehus

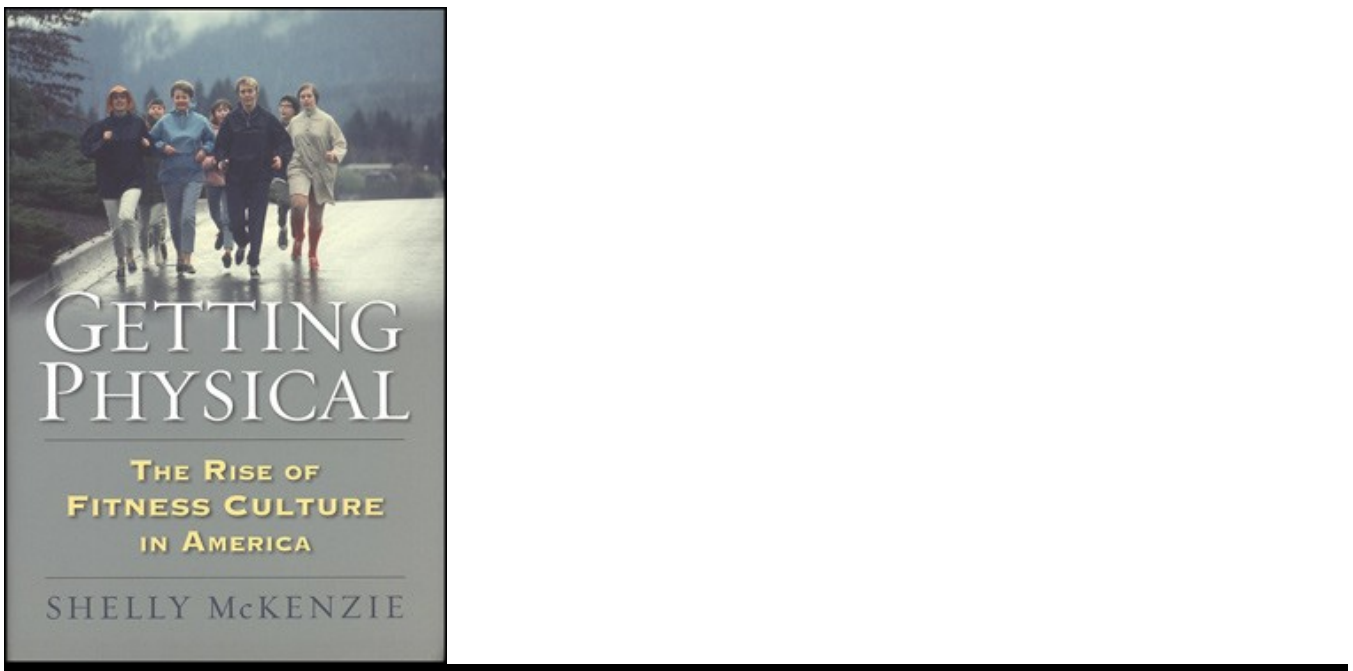

McKenzie, Shelly

Getting physical

The rise of fitness culture in America. 254 s, ill. Lawrence, KS: University Press of Kansas, 2013. Pris USD 35

ISBN 978-0-7006-1906-1

Denne boken, skrevet av en historiker, anmeldt av en medisiner uten faghistorisk bakgrunn, belyser samfunnshendelser og trender som førte til at fysisk trening ble moderne i USA i etterkrigstiden.

Teksten er noe tung å lese. Det skyldes at den har få illustrasjoner og underkapitler, og et vell av noter og referanser, som er tillitsvekkende, men som også hemmer flyten i lesingen. 
De fem kapitlene er Fitness begins in the high chair, om fysisk aktivitet i etterkrigstiden, Your honeymoon figure, om hvordan kvinnene ble påvirket til å trene for å gjenerobre figuren fra før ekteskapet, The heart of the man in the gray flannel suit, om hvordan mennene skulle trene for å unngå hjerteinfarkt, Run for your life, om joggebølgen, og Temples of the body, om helseklubbene og fitnesskulturen.

Forfatteren setter søkelys på etterkrigstidens velstandsøkning, forstadskulturen, medfølgende bilisme og påfølgende passive livsstil og overvekt. Datidens kulturelle idealer, reklame, medier, næringslivsbidrag og politiske innspill refereres rikelig og er interessant dette som til sammen formet vår nære samtid. Kjønn, rase og kroppsidealer styrte i høy grad hvordan trening ble promotert. Kampanjepregede, flertydige slagord som «Fitness can keep U.S. strong» illustrerer ånden som rådet. Ikoner preget nasjonens selvbilde. Det klassiske bildet fra 1979 av president Jimmy Carter idet han kollaberer under et $10 \mathrm{~km}$ langt løp bidro nok til å svekke inntrykket av presidentens handlekraft.

Middelaldrende amerikanske menn fikk hjerteinfarkt i økende grad. Sykdomstrusselen manifesterte seg ytterligere da presidenten selv, Dwight D. Eisenhower, fikk hjerteinfarkt i 1955. Den folkelige forståelsen var at ingen kunne føle seg sikre, selv ikke presidenten. Man henvendte seg til kvinner for å få mennene til å leve sunnere. En boktittel som How not to kill your husband ga kvinner ansvar for mannens helse.

I 1968 ble joggebølgen dratt i gang. I 1984 dør joggeguruen, James Fixx, under en treningstur. Det ga vann på mølla for dem som mente at fysisk aktivitet var uheldig. Selv om flere leger var forkjempere for aktivitetsbølgen, var det også mange som var imot.

Boken synes god innenfor sine rammer, men er ikke en bok som en norsk lege trenger i sitt daglige virke. Derimot er den interessant for idrettsinteresserte, for dem som arbeider med tilrettelegging av fysisk aktivitet i befolkningen, og den er svært relevant for dem som forsker på hvordan kultur påvirker helse og fysisk aktivitet.

McKenzie tegner et samfunnsbilde basert på et meget bredt kildemateriale og dokumenterer svært leseverdig nærhistorien som mange av Tidsskriftets lesere har et forhold til - fordi de selv har opplevd hele eller deler av den.

Publisert: 9. desember 2014. Tidsskr Nor Legeforen. DOI: 10.4045/tidsskr.14.1013

(C) Tidsskrift for Den norske legeforening 2023. Lastet ned fra tidsskriftet.no 26. april 2023. 